\title{
The recent progress of neoadjuvant chemotherapy in triple negative breast cancer: A short review
}

\author{
Michael Liontos ${ }^{1}$, Sophia Karageorgopoulou ${ }^{2}$, Vasiliki Michalaki ${ }^{2}$, J ohn Contis ${ }^{3}$, Evangelos \\ Bournakis $^{2}$, John Vassiliou ${ }^{3}$, Meletios-Athanasios Dimopoulos ${ }^{1}$, Christos A. Papadimitriou ${ }^{1,2}$ \\ 1. Department of Clinical Therapeutics, Alexandra Hospital, National and Kapodistrian University of Athens School of \\ Medicine, Greece. 2. Oncology Unit, Second Department of Surgery, Aretaieion Hospital, National and Kapodistrian \\ University of Athens School of Medicine, Greece. 3. Second Department of Surgery, Aretaieion Hospital, National and \\ Kapodistrian University of Athens School of Medicine, Greece.
}

Correspondence: Christos A. Papadimitriou. Address: Oncology Unit, 2nd Dept. of Surgery, Aretaieion Hospital, V. Sophias 76, 11528 Athens, Greece. Email: chr_papadim@yahoo.gr

Received: January 31, 2015

Accepted: March 12, 2015

Online Published: May 14, 2015

DOI : $10.5430 /$ jst.v5n2p18

URL: http://dx.doi.org/10.5430/jst.v5n2p18

\section{Abstract}

Triple negative breast cancer (TNBC) encompasses tumors that do not express either the estrogen receptor (ER) or the progesterone receptor (PR) and also do not overexpress the Human Epidermal growth factor Receptor 2 (HER2). This is a heterogenous group of tumors that significantly overlaps with both basal-like tumors and BRCA1/BRCA2 mutationassociated tumors. TNBC is highly aggressive in nature and exhibits worse prognosis than the other subtypes of breast cancer, despite its increased chemosensitivity. Neoadjuvant chemotherapy (NACT) is a treatment option regularly incorporated in clinical practice to improve subsequent surgical management. In parallel, allows rating of the pathological compete response (pCR) which is associated with the prognosis of these patients and evaluates the efficacy of the applied treatment as well. Platinum-based regimens and novel targeted therapies have shown some benefit in TNBC, though an unmet need for improved therapeutic strategies in this patient population still remains. In this review, the latest progresses in NACT in TNBC are discussed, along with the improved understanding of molecular targets and useful biomarkers in this group of patients.

\section{Key words}

Triple negative breast cancer, Neoadjuvant chemotherapy, Progesterone receptor

\section{Introduction}

Breast cancer is a heterogenous disease and clinical, histopathological and molecular characteristics have been used for its classification. These cases that by immunohistochemical means do not express either the estrogen receptor or the progesterone receptor and also do not overexpress the HER2 are designated as "Triple Negative" Breast Carcinomas (TNBC) ${ }^{[1]}$. TNBCs account for $15 \%$ of all breast carcinomas and are usually diagnosed in younger women with advanced stage disease ${ }^{[2,3]}$. TNBCs also tend to recur earlier and show a more aggressive metastatic phenotype than other types of this disease ${ }^{[4]}$. The lack of Hormone Receptor (HR) expression as well as the absence of HER2 overexpression in this subset of tumors is translated into clinical practice as shortage of therapeutic options for TNBC, essentially rendering a 
deeper understanding in the pathogenesis of TNBC. The heterogeneity of this subtype of breast carcinoma and the role of NACT in its management will be discussed in this review, encompassing major trials announced up to the end of 2014.

\section{TNBC-subtypes}

In 2000, Perou et al. ${ }^{[5]}$ identified five distinct subtypes of breast cancer by analyzing gene profiling produced by cDNA microarrays from 40 breast cancer patients. Among them, "basal-like" tumors that expressed breast basal cell keratins and were negative for HR expression demonstrated similarities with TNBC. However, not all TNBC are "basal-like" and these two terms cannot be used interchangeably. Histologically, the majority of TNBCs are invasive ductal carcinomas not-otherwise specified (IDC-NOS), but also rare entities such as medullary and metaplastic carcinomas, as well as apocrine and adenoid cystic carcinomas share the triple negative phenotype ${ }^{[6,7]}$. Analogously, the heterogeneity among TNBCs is confirmed by molecular analysis ${ }^{[8,9]}$. Although basal-like phenotype predominates among TNBCs -characterized by BRCA1/2 deficiency ${ }^{[10,11]}$ and frequent $p 53$ mutations ${ }^{[12]}$ - other subtypes have also emerged recently. Among them the claudin-low phenotype is the most prevalent one ${ }^{[13,14]}$. These tumors demonstrate decreased expression of claudin proteins, which are important components of tight junctions between epithelial cells, and express markers of Epithelial to Mesenchymal Transition (EMT) ${ }^{[15,16]}$. A recent molecular profiling of TNBCs conducted by Lehmann et al. ${ }^{[17]}$ identified 6 TNBC subtypes displaying unique gene expression and ontologies, including 2 basal-like (BL1 and BL2), an immunomodulatory (IM), a mesenchymal (M), a mesenchymal stem-like (MSL), and a luminalandrogen receptor (LAR) subtype, the latter including patients with decreased relapse-free survival and characterized by androgen receptor (AR) signaling. Despite TNBC as a whole is considered more chemosensitive than other subtypes of breast cancer, differences in the efficacy of chemotherapeutic regimens have been shown also among subtypes of TNBC providing evidence that this should not be considered as a unique entity and paving the way for new targeted therapies based on the molecular characteristics of each subtype.

\section{The rationale of neoadjuvant chemotherapy (NACT)}

Traditionally, neoadjuvant chemotherapy (NACT) is used in patients with unresectable locally advanced breast cancer in an attempt to render the disease operable. However, the use of neoadjuvant chemotherapy has been extended also in primary operable tumors, in order to allow greater conservation of the breast and avoid mastectomy. From a clinical point of view, this approach is acceptable as shown by a recent meta-analysis demonstrating no difference in overall survival (OS) of patients with breast cancer subjected to surgery, independently of the setting chemotherapy was administered (adjuvant or NACT) ${ }^{[18]}$. In addition, response to NACT may also allow the modification of adjuvant radiotherapy decreasing the long-term consequences of breast cancer survivors, but this remains to be elucidated. NACT also offers the clinician two significant information: response to treatment thus enabling the appropriate design of subsequent therapies and prognostic information for the patient. It is now acceptable that patients who achieve pathological complete response (pCR) after NACT appear to have significantly lower recurrence rate in comparison to those with residual disease upon surgery ${ }^{[19-21]}$. This is particularly true for patients with TNBC ${ }^{[20,22]}$ and those with HER2-positive tumors treated with trastuzumab ${ }^{[21]}$. The last finding provides one more use for NACT: that of allowing investigators to examine efficacy of new chemotherapeutic regimens, as well as the modulation of biomarkers from initial biopsy to definitive surgery in order to gain approval for new treatments. This is particularly useful for aggressive subtypes of breast cancer, such as TNBC, and this modality has been adopted from regulatory agencies for providing accelerated approval for new drugs since studies based on adjuvant chemotherapy take much more time to be completed ${ }^{[23]}$.

\section{Neoadjuvant chemotherapy in TNBC}

NACT is an essential clinical approach in specific inoperable locally advanced breast carcinomas aiming at reducing tumor size and rendering the tumor operable. Historically, though, the first neoadjuvant trials aimed at investigating 
whether presurgical chemotherapy could be an alternative to postsurgical treatment in terms of disease-free survival (DFS) and overall survival (OS) and mainly in which population this is possible. This was based on the assumption that presurgical systematic therapy would act on a less multiclonal population of malignant cells increasing its efficacy in comparison to the adjuvant chemotherapy. In 2001, Wolmark et al. presented the results from the National Surgical Adjuvant Breast and Bowel Project (NSABP) B-18 protocol comparing four cycles of doxorubicin and cyclophosphamide applied either in the neoadjuvant or adjuvant setting ${ }^{[24]}$ in patients with operable breast cancer. No statistical significant differences, regarding DFS and OS, were noted between the two groups, despite patients with better primary tumor response had a favorable outcome. This result was later confirmed by a meta-analysis of nine studies -including the NSABP B-18- comparing adjuvant chemotherapy to NACT ${ }^{[18]}$.

The correlation between complete response of the primary tumor after NACT and improved DFS and OS was repeatedly shown by various studies ${ }^{[25-27]}$. Patients with TNBC have increased rates of pCR in comparison to other histological types of breast cancer and these patients have an excellent prognosis ${ }^{[28]}$. However, those that do not acquire pCR have a much poorer prognosis despite the type of chemotherapy they received, and account for the overall worse outcome of this histology that is usually referred as the "triple-negative paradox" ${ }^{229]}$. These were clearly demonstrated by a meta-analysis performed by von Minckwitz et al., encompassing seven prior studies of NACT in breast cancer ${ }^{[30-37]}$. This study clearly indicated that $\mathrm{pCR}$ defined as absence of invasive cancer in the breast and axillary nodes, and absence of ductal carcinoma in situ (ypT0ypN0) is a suitable surrogate marker of good prognosis for luminal B, HER2-positive and TNBC patients prompting for efforts to maximize pCR rates after NACT in these groups. Classical anthracycline- and taxane-based chemotherapy regimens used in the studies that were included in the von Minckwitz meta-analysis led to pCR in $31 \%$ of TNBC patients.

Attempts to improve NACT efficacy included intensified schemes and incorporation of new drugs in the already existed regimens. Following the increased efficacy of dose-dense chemotherapeutic regimens in the adjuvant setting, the implementation of such schemes in the presurgical setting also provided increased pCR rates in TNBC patients. In the PREPARE study ${ }^{[35]}$, dose-dense sequential chemotherapy with epirubicin and cyclophosphamide followed by paclitaxel and finally by CMF led to a pCR rate of $44.6 \%$ in the TNBC group in comparison to the $30.4 \%$ achieved with the conventional schemes. Analogous results were documented with the GEPARDUO study ${ }^{[30]}$ where patients received four cycles of docetaxel and doxorubicin, every 2 weeks, with the support of filgrastim.

Another therapeutic option is the incorporation of new drugs into regimens already established. BRCA1germline mutations carriers often present tumors with basal-like morphology and their genomic alterations, as examined by microarray-based comparative genomic hybridization (array CGH), are similar to those in TNBC patients ${ }^{[10]}$. Finally, BRCA1 promoter methylation is a frequent event in TNBC patients and it predicts sensitivity to adjuvant chemotherapy ${ }^{[38]}$. In cancer cell lines and xenografted tumors, $B R C A 1 \mathrm{CpG}$ island promoter hypermethylation-associated silencing predicts enhanced sensitivity to platinum-derived drugs to the same extent as BRCA1 mutations. Most importantly, BRCA1 hypermethylation proves to be a predictor of longer time to relapse and improved OS in ovarian cancer patients undergoing chemotherapy with cisplatin ${ }^{[39]}$. Under this perspective single agent cisplatin NACT resulted in pCR in $21 \%$ of patients with TNBC ${ }^{[40]}$, while carboplatin and taxane combinations resulted in even greater response rates ${ }^{[41,42]}$. Despite taxane- and anthracycline-based regimens remain the mainstay for TNBC neoadjuvant treatment, these encouraging results indicate that carboplatin-taxane regimens could be a very efficacious non-anthracycline containing combination. An ongoing phase III trial of the Netherlands Cancer Institute, investigates whether intensifying alkylating agents NACT could improve response rates in comparison to standard anthracycline- and taxane-based preoperative chemotherapy ${ }^{[43]}$. Analogously, in the randomized phase II GEPARSIXTO trial the addition of carboplatin to the standard anthracyclinetaxane neoadjuvant regimen increased $\mathrm{pCR}$ ratio to over $50 \%$ of patients with $\mathrm{TNBC}{ }^{[44]}$. This increase was statistical significant but was also associated with an increase in grade 3 and 4 hematological adverse events and diarrhea. Also, the number of patients that discontinued treatment due to toxicity was significantly greater in the carboplatin arm. 
An alternative approach has emerged by the substitution of paclitaxel by its nanoparticle albumin-bound formulation. Weekly Nab-paclitaxel has been shown increased efficacy versus 3-weekly docetaxel administration in patients with metastatic breast cancer ${ }^{[45]}$. Analogously, nab-paclitaxel was associated with increased pCR rates compared to paclitaxel in taxane-first sequential taxane/anthracycline neoadjuvant treatment (GeparSepto trial) ${ }^{[46]}$. This was particularly evident in the TNBC patients population, where nab-paclitaxel increased statistically significant pCR rate from $25.7 \%$ to $48.2 \%$ ( $P$ $<.001)$. This is a very important finding, as we know that pCR is most prognostic for outcome in this specific high-risk subtype, which comprises about $15 \%$ of all breast cancers.

\section{Novel agents in the neoadjuvant treatment of TNBC}

The efficacy of taxane- and anthracycline-based regimens in inducing pCR after neoadjuvant administration has reached a plateau. This became particularly evident in the study of Bear et al. ${ }^{[4]}$ who randomly assigned patients with operable, HER2-negative breast cancer to receive neoadjuvant therapy consisting of docetaxel, docetaxel plus capecitabine, or docetaxel plus gemcitabine for four cycles, with all regimens followed by treatment with doxorubicin-cyclophosphamide for four cycles. The addition of capecitabine or gemcitabine to docetaxel therapy, as compared with docetaxel therapy alone, did not significantly increase the rate of pathological complete response. In the same study, patients were also randomized to receive or not bevacizumab for the first six cycles of chemotherapy. The addition of the monoclonal antibody to NACT significantly increased the rate of pathological complete response and this benefit tended to be seen in patients with a high tumor grade and positive hormone receptors. Improved understanding of the molecular pathways regulating TNBC pathogenesis allows now for the introduction of targeted therapies that could provide clinical benefit. Based on the rationale that proangiogenic pathways are not extensively deregulated in early breast cancer, the anti-VEGF antibody bevacizumab could prove more efficacious in the neoadjuvant setting in comparison to the results shown by its use in patients with metastatic disease ${ }^{[47-49]}$. In the GEPARQUINTO trial ${ }^{[50]}$, bevacizumab indeed improved pCR rate in the studied population. The effect though was most prominent in patients with TNBC where the pCR rate raised from $27 \%$ with the conventional regimen of epirubicin plus cyclophosphamide followed by docetaxel to $39 \%$ when bevacizumab was added. More recently, in a Korean phase II study (KCSG BR-0905)neoadjuvant therapy with bevacizumab, docetaxel and carboplatin resulted in a $\mathrm{pCR}$ rate of $42 \%$ in patients with $\mathrm{TNBC}^{[51]}$. This rate was similar to that observed in another phase II study that combined bevacizumab with docetaxel and cyclophosphamide for four cycles followed by four cycles of doxorubicin ${ }^{[52]}$, as well as with the rate of pCR achieved among patients with TNBC in the GEPARQUINTO trial as previously described. Further validation of these results is anticipated in order to clarify what could be the role of bevacizumab in the neoadjuvant setting of TNBC and specifically to delineate the subgroup of women who could benefit most and furthermore which type of chemotherapy is most suitable. The CALGB 40603 study, a phase II 2 X2 factorial trial, will examine both the benefit of adding carboplatin to the taxane-anthracycline backbone, as well as the effect of incorporating bevacizumab in the preoperative chemotherapy of operable TNBC.

One of the most frequently altered pathway in breast cancer and specifically in TNBC is PI3K/Akt/mTor pathway ${ }^{[53]}$. Currently, everolimus an mTor inhibitor has gain regulatory approval for use in women with Hormone Receptor positive metastatic breast cancer that progress after first line hormonal treatment ${ }^{[54]}$. However, this drug as well as many others under development that inhibit at different levels the PI3K/Akt/mTor pathway has also been studied in TNBC patients. Everolimus in the neoadjuvant setting was studied in an open label randomized phase II trial in combination with the Paclitaxel-FEC regimen ${ }^{[55]}$. The addition of everolimus increased both Response Rate and pCR but not to a statistical significant extent. Furthermore, response to everolimus was not related to the downregulation of mTor pathway as shown by biomarker analysis. It should be noted though that everolimus was administered weekly at $30 \mathrm{mg}$ per os in this study instead of the approved daily scheduled of $10 \mathrm{mg}$. Everolimus addition to paclitaxel in the neoadjuvant setting also failed to increase $\mathrm{pCR}$ rates in TNBC patients that were non-responsive to epirubicin-cyclophosphamide \pm bevacizumab in the GeparQuinto study ${ }^{[56]}$. Long-term outcomes of these studies are awaited, but they clearly signify these agents may be beneficial, but better biomarkers should be discovered to guide for optimal selections of patients. 
In TNBC, higher EGFR expression and increased EGFR gene copy number has been associated with worse prognosis ${ }^{[57,58]}$. Also the EGFR expression is higher in TNBC among breast cancer patients ${ }^{[59]}$. These data prompted two phase II ramdomized studies that tested the role of cetuximab in patients with metastatic TNBC. Cetuximab used as monotherapy provided poor response rates ${ }^{[60]}$, despite the EGFR pathway is active in these patients indicating that alternative pathway activation mechanisms exist in these patients. The addition of cetuximab though to cisplatin improved responses in the metastatic setting in comparison to cisplatin monotherapy despite the study did not met predefined criteria for OS and PFS ${ }^{[61]}$ indicating that EGFR inhibition could have therapeutic benefit in these patients. Another EGFR inhibitor, erlotinib, has also shown encouraging pCR rates when combined with Carboplatin-Docetaxel chemotherapy in a small phase II trial ${ }^{[62]}$. Under this perspective a trial testing erlotinib along with chemotherapy in the neoadjuvant setting in women with TNBC is underway (NCT00491816). Finally, cetuximab is currently tested in combination with ixabepilone that has shown efficacy in a previous neoadjuvant trial in TNBC patients ${ }^{[63]}$ in the NCT01097642 clinical trial.

Another attractive target in TNBC is PARP inhibition. In BRCA1/2 mutated tumours further inhibition of PARP provokes cell death through "synthetic lethality" ${ }^{[64]}$. TNBC shares clinical and pathological features with hereditary BRCA1-related breast cancer and BRCA1 deficiency in these tumors is frequent through various mechanisms leading TNBC to acquire a "BRCAness" phenotype ${ }^{[10]}$. Furthermore, analysis of cPARP expression in breast cancer patients treated with neoadjuvant chemotherapy in the GEPARTRIO trial indicated that cPARP was a strong predictive marker for pCR in triple negative tumors, while the same time was prognostic for more aggressive tumors resulting in worst OS and DFS for patients that did not achieve $\mathrm{pCR}^{[65]}$. Despite these promising indications and the positive results from a randomized phase II trial ${ }^{[66]}$, iniparib a third generation PARP inhibitor failed to improve the outcome in the metastatic setting when added to cytotoxic chemotherapy ${ }^{[67]}$. Analogously, the interim analysis of the SOLTINeoPARP trial, a randomized phase II study that examined the efficacy of iniparib addition to weekly paclitaxel in the neoadjuvant setting of TNBC, failed to meet its primary endpoint that was pCR improvement ${ }^{[68]}$. Newer in vitro data though recognized that iniparib is not a selective PARP inhibitor ${ }^{[69,70]}$ and its antineoplastic action could be attributed to the modification of cystein-containing proteins ${ }^{[69]}$, explaining its failure in the TNBC population. Other selective third generation PARP inhibitors, namely olaparib and veliparib, could be more effective and are investigated in clinical trials.

Table 1. Clinical trials investigating the role of targeted therapies in the neoadjuvant treatment of triple negative breast cancer

\begin{tabular}{|c|c|c|c|}
\hline $\begin{array}{l}\text { Trial Identifier } \\
\text { No }\end{array}$ & Phase & Investigated regimen & Primary Outcome \\
\hline NCT00887575 & $\mathrm{I} / \mathrm{II}$ & Paclitaxel/Carboplatin/Sunitinib & $\mathrm{pCR}$ \\
\hline NCT01617668 & II & Paclitaxel and LCL-161/placebo & $\mathrm{pCR}$ \\
\hline NCT00491816 & II & Neoadjuvant chemotherapy (physician discretion) and erlotinib & $\mathrm{pCR}$ \\
\hline NCT00777673 & II & Nab-paclitaxel/carboplatin followed by Docetaxel/cylcophosphamide with bevacizumab & $\mathrm{pCR}$ \\
\hline NCT01097642 & II & Cetuximab/ixabepilone & $\mathrm{pCR}$ \\
\hline NCT00600249 & II & Cetuximab/Docetaxel & $\mathrm{pCR}$ \\
\hline NCT01238133 & I & Gamma-secretase/Notch signalling pathway inhibitor RO4929097/Docetaxel/Carboplatin & $\begin{array}{l}\text { MTD/DLT of } \\
\text { RO4929097 }\end{array}$ \\
\hline NCT01194869 & II & Sorafenib/Cisplatin followed by ddPaclitaxel & $\mathrm{pCR}$ \\
\hline NCT01818063 & II & Paclitaxel/carboplatin/Veliparib or placebo followed by Doxorubicin/Cyclophosphamide & $\mathrm{pCR}$ \\
\hline NCT00861705 & II & Paclitaxel \pm Carboplatin \pm Bevacizumab followed by Doxorubicin/Cyclophosphamide & $\mathrm{pCR}$ \\
\hline
\end{tabular}

\section{Future perspectives}

TNBC is a heterogenous disease that lack standard therapeutic approaches either in the early or advanced disease. Novel molecular techniques have though provided helpful insight in the molecular pathogenesis of this entity allowing for improved understanding of the several subtypes of TNBC ${ }^{[8,12,15]}$. These could be particularly useful in the neoadjuvant setting, that apart of providing optimal clinical benefit in patients with primarily inoperable as well as operable breast 
cancer, allow also for gathering valuable information for recognizing biomarkers and novel therapeutic strategies. Novel targeted therapies have lately incorporated in regimens used in the preoperative setting in TNBC and many more are under investigation (see Table 1). The results of these trials will prove how beneficiary this targeted strategy could be for the patients, targeting a new era with less chemotherapy but more efficient regimens.

\section{References}

[1] Oakman C, Viale G, Di Leo A. Management of triple negative breast cancer. Breast (Edinburgh, Scotland). 2010 ; $19(5)$ : $312-321$. PMid:20382530. http://dx.doi.org/10.1016/j.breast.2010.03.026

[2] Bauer KR, et al. Descriptive analysis of estrogen receptor (ER)-negative, progesterone receptor (PR)-negative, and HER2-negative invasive breast cancer, the so-called triple-negative phenotype: a population-based study from the California cancer Registry. Cancer. 2007; 109(9): 1721-8. PMid:17387718. http://dx.doi.org/10.1002/cncr.22618

[3] Azim HA, et al. Elucidating prognosis and biology of breast cancer arising in young women using gene expression profiling. Clin Cancer Res. 2012; 18(5): 1341-51. PMid:22261811. http://dx.doi.org/10.1158/1078-0432.CCR-11-2599

[4] Haffty BG, et al. Locoregional relapse and distant metastasis in conservatively managed triple negative early-stage breast cancer. J Clin Oncol. 2006; 24(36): 5652-7. PMid:17116942. http://dx.doi.org/10.1200/JCO.2006.06.5664

[5] Perou CM, et al. Molecular portraits of human breast tumours. Nature. 2000; 406(6797): 747-52. PMid:10963602. http://dx.doi.org/10.1038/35021093

[6] Bae S, et al. The prognoses of metaplastic breast cancer patients compared to those of triple-negative breast cancer patients. Breast Cancer Research and Treatment. 2011; 126(2): 471-478. PMid:21287362. http://dx.doi.org/10.1007/s10549-011-1359-8

[7] Montagna E, et al. Heterogeneity of Triple-Negative Breast Cancer: Histologic Subtyping to Inform the Outcome. Clinical Breast Cancer. 2013; 13(1): 31-39. PMid:23098574. http://dx.doi.org/10.1016/j.clbc.2012.09.002

[8] Turner $\mathrm{N}$, et al. Integrative molecular profiling of triple negative breast cancers identifies amplicon drivers and potential therapeutic targets. Oncogene. 2010; 29(14): 2013-23. PMid:20101236. http://dx.doi.org/10.1038/onc.2009.489

[9] Bertucci F, et al. How basal are triple-negative breast cancers? Int J Cancer. 2008; 123(1): 236-40. PMid:18398844. http://dx.doi.org/10.1002/ijc. 23518

[10] Lips EH, et al. Triple-negative breast cancer: BRCAness and concordance of clinical features with BRCA1-mutation carriers. Br J Cancer. 2013; 108(10): 2172-7. PMid:23558900. http://dx.doi.org/10.1038/bjc.2013.144

[11] Oonk AM, et al. Clinical correlates of 'BRCAness' in triple-negative breast cancer of patients receiving adjuvant chemotherapy. Ann Oncol. 2012; 23(9): 2301-5. PMid:22357256. http://dx.doi.org/10.1093/annonc/mdr621

[12] Rakha EA, et al. Triple-Negative Breast Cancer: Distinguishing between Basal and Nonbasal Subtypes. Clinical Cancer Research, 2009; 15(7): 2302-2310. PMid:19318481. http://dx.doi.org/10.1158/1078-0432.CCR-08-2132

[13] Hennessy BT, et al. Characterization of a Naturally Occurring Breast Cancer Subset Enriched in Epithelial-to-Mesenchymal Transition and Stem Cell Characteristics. Cancer Research. 2009. 69(10): 4116-4124. PMid:19435916. http://dx.doi.org/10.1158/0008-5472.CAN-08-3441

[14] Prat A, et al. Phenotypic and molecular characterization of the claudin-low intrinsic subtype of breast cancer. Breast Cancer Research. 2010; 12(5): R68. PMid:20813035. http://dx.doi.org/10.1186/bcr2635

[15] Perou CM. Molecular Stratification of Triple-Negative Breast Cancers. The Oncologist. 2010; 15(suppl 5): 39-48. PMid:21138954. http://dx.doi.org/10.1634/theoncologist.2010-S5-39

[16] Adamo B, Anders C. Stratifying triple-negative breast cancer: which definition(s) to use? Breast Cancer Research. 2011; 13(2): 105. PMid:21457488. http://dx.doi.org/10.1186/bcr2852

[17] Lehmann BD, et al. Identification of human triple-negative breast cancer subtypes and preclinical models for selection of targeted therapies. The Journal of Clinical Investigation. 2011; 121(7): 2750-2767. PMid:21633166. http://dx.doi.org/10.1172/JCI45014

[18] Mauri D, Pavlidis N, Ioannidis JP. Neoadjuvant versus adjuvant systemic treatment in breast cancer: a meta-analysis. J Natl Cancer Inst. 2005; 97(3): 188-94. PMid:15687361. http://dx.doi.org/10.1093/jnci/dji021

[19] Yoshioka T, et al. Prognostic significance of pathologic complete response and Ki67 expression after neoadjuvant chemotherapy in breast cancer. Breast Cancer. 2013: 1-7.

[20] von Minckwitz G, et al. Definition and Impact of Pathologic Complete Response on Prognosis After Neoadjuvant Chemotherapy in Various Intrinsic Breast Cancer Subtypes. Journal of Clinical Oncology. 2012. 30(15): 1796-1804. PMid:22508812. http://dx.doi.org/10.1200/JCO.2011.38.8595

[21] Untch M, et al. Pathologic Complete Response After Neoadjuvant Chemotherapy Plus Trastuzumab Predicts Favorable Survival in Human Epidermal Growth Factor Receptor 2-Overexpressing Breast Cancer: Results From the TECHNO Trial of the AGO and 
GBG Study Groups. Journal of Clinical Oncology. 2011; 29(25): 3351-3357. PMid:21788566.

http://dx.doi.org/10.1200/JCO.2010.31.4930

[22] Liedtke C, et al. Response to Neoadjuvant Therapy and Long-Term Survival in Patients With Triple-Negative Breast Cancer. Journal of Clinical Oncology. 2008; 26(8): 1275-1281. PMid:18250347. http://dx.doi.org/10.1200/JCO.2007.14.4147

[23] Prowell TM, Pazdur R. Pathological Complete Response and Accelerated Drug Approval in Early Breast Cancer. New England Journal of Medicine. 2012; 366(26): 2438-2441. PMid:22646508. http://dx.doi.org/10.1056/NEJMp1205737

[24] Wolmark N, et al. Preoperative Chemotherapy in Patients with Operable Breast Cancer: Nine-Year Results from National Surgical Adjuvant Breast and Bowel Project B-18. JNCI Monographs. 2001; 2001(30): 96-102.

http://dx.doi.org/10.1093/oxfordjournals.jncimonographs.a003469

[25] Rastogi P, et al. Concurrent bevacizumab with a sequential regimen of doxorubicin and cyclophosphamide followed by docetaxel and capecitabine as neoadjuvant therapy for HER2- locally advanced breast cancer: a phase II trial of the NSABP Foundation Research Group. Clin Breast Cancer. 2011; 11(4): 228-34. PMid:21684812. http://dx.doi.org/10.1016/j.clbc.2011.04.001

[26] Chang HR, et al. Differential response of triple-negative breast cancer to a docetaxel and carboplatin-based neoadjuvant treatment. Cancer. 2010; 116(18): 4227-37. PMid:20549829. http://dx.doi.org/10.1002/cncr.25309

[27] von Minckwitz G, et al. Capecitabine in Addition to Anthracycline- and Taxane-Based Neoadjuvant Treatment in Patients With Primary Breast Cancer: Phase III GeparQuattro Study. Journal of Clinical Oncology. 2010; 28(12): 2015-2023. PMid:20308671. http://dx.doi.org/10.1200/JCO.2009.23.8303

[28] Rouzier R, et al. Breast Cancer Molecular Subtypes Respond Differently to Preoperative Chemotherapy. Clinical Cancer Research. 2005; 11(16): 5678-5685. PMid:16115903. http://dx.doi.org/10.1158/1078-0432.CCR-04-2421

[29] Carey LA, et al. The triple negative paradox: primary tumor chemosensitivity of breast cancer subtypes. Clin Cancer Res. 2007; 13(8): 2329-34. PMid:17438091. http://dx.doi.org/10.1158/1078-0432.CCR-06-1109

[30] von Minckwitz G, et al. Doxorubicin With Cyclophosphamide Followed by Docetaxel Every 21 Days Compared With Doxorubicin and Docetaxel Every 14 Days As Preoperative Treatment in Operable Breast Cancer: The GEPARDUO Study of the German Breast Group. Journal of Clinical Oncology. 2005; 23(12): 2676-2685. PMid:15837982. http://dx.doi.org/10.1200/JCO.2005.05.078

[31] Minckwitz G, et al. A multicentre phase II study on gefitinib in taxane- and anthracycline-pretreated metastatic breast cancer. Breast Cancer Research and Treatment. 2005; 89(2): 165-172. PMid:15692759. http://dx.doi.org/10.1007/s10549-004-1720-2

[32] von Minckwitz G, et al. Neoadjuvant Vinorelbine-Capecitabine Versus Docetaxel-Doxorubicin-Cyclophosphamide in Early Nonresponsive Breast Cancer: Phase III Randomized GeparTrio Trial. Journal of the National Cancer Institute. 2008; 100(8): 542-551. PMid:18398097. http://dx.doi.org/10.1093/jnci/djn085

[33] Untch M, et al. Intensive dose-dense compared with conventionally scheduled preoperative chemotherapy for high-risk primary breast cancer. J Clin Oncol. 2009; 27(18): 2938-45. PMid:19364964. http://dx.doi.org/10.1200/JCO.2008.20.3133

[34] Untch M, et al. Neoadjuvant treatment with trastuzumab in HER2-positive breast cancer: results from the GeparQuattro study. $\mathrm{J}$ Clin Oncol. 2010; 28(12): 2024-31. PMid:20308670. http://dx.doi.org/10.1200/JCO.2009.23.8451

[35] Untch M, et al. PREPARE trial: a randomized phase III trial comparing preoperative, dose-dense, dose-intensified chemotherapy with epirubicin, paclitaxel, and CMF versus a standard-dosed epirubicin-cyclophosphamide followed by paclitaxel with or without darbepoetin alfa in primary breast cancer--outcome on prognosis. Ann Oncol. 2011; 22(9): 1999-2006. PMid:21382868. http://dx.doi.org/10.1093/annonc/mdq713

[36] Untch M, et al. Pathologic complete response after neoadjuvant chemotherapy plus trastuzumab predicts favorable survival in human epidermal growth factor receptor 2-overexpressing breast cancer: results from the TECHNO trial of the AGO and GBG study groups. J Clin Oncol. 2011; 29(25): 3351-7. PMid:21788566. http://dx.doi.org/10.1200/JCO.2010.31.4930

[37] Untch M, von Minckwitz G. Neoadjuvant Treatment of Breast Cancer. Breast Care (Basel). 2011; 6(6): 417. PMid:22419893. http://dx.doi.org/10.1159/000335444

[38] Xu Y, et al. Promoter methylation of BRCA1 in triple-negative breast cancer predicts sensitivity to adjuvant chemotherapy. Ann Oncol. 2013; 24(6): 1498-505. PMid:23406733. http://dx.doi.org/10.1093/annonc/mdt011

[39] Stefansson OA, et al. "BRCA1" epigenetic inactivation predicts sensitivity to platinum-based chemotherapy in breast and ovarian cancer. Epigenetics. 2012; 7(11): 1225-1229. PMid:23069641. http://dx.doi.org/10.4161/epi.22561

[40] Silver DP, et al. Efficacy of Neoadjuvant Cisplatin in Triple-Negative Breast Cancer. Journal of Clinical Oncology. 2010; 28(7): 1145-1153. PMid:20100965. http://dx.doi.org/10.1200/JCO.2009.22.4725

[41] Chen XS, et al. Weekly paclitaxel plus carboplatin is an effective nonanthracycline-containing regimen as neoadjuvant chemotherapy for breast cancer. Annals of Oncology; 2010; 21(5): 961-967. PMid:20211870. http://dx.doi.org/10.1093/annonc/mdq041 
[42] Sikov WM, et al. Frequent Pathologic Complete Responses in Aggressive Stages II to III Breast Cancers With Every-4-Week Carboplatin and Weekly Paclitaxel With or Without Trastuzumab: A Brown University Oncology Group Study. Journal of Clinical Oncology. 2009; 27(28): 4693-4700. PMid:19720916. http://dx.doi.org/10.1200/JCO.2008.21.4163

[43] Institute TNC. Randomized Phase II/III Study of Individualized Neoadjuvant Chemotherapy in "Triple Negative" Breast Tumors. 2010.

[44] von Minckwitz G, et al. Neoadjuvant carboplatin in patients with triple-negative and HER2-positive early breast cancer (Gepar Sixto; GBG 66): a randomised phase 2 trial. Lancet Oncol. 2014; 15(7): 747-56. http://dx.doi.org/10.1016/S1470-2045(14)70160-3

[45] Gradishar WJ, et al. Significantly longer progression-free survival with nab-paclitaxel compared with docetaxel as first-line therapy for metastatic breast cancer. J Clin Oncol. 2009; 27(22): 3611-9. PMid:19470941. http://dx.doi.org/10.1200/JCO.2008.18.5397

[46] Untch M, Jackisch C, Schneeweiß A. A randomized phase III trial comparing neoadjuvant chemotherapy with weekly nanoparticle-based paclitaxel with solventbased paclitaxel followed by anthracyline/ cyclophosphamide for patients with early breast cancer (GeparSepto); in 2014 San Antonio Breast Cancer Symposium. San Antonio, Texas; 2014.

[47] Miller K, et al. Paclitaxel plus Bevacizumab versus Paclitaxel Alone for Metastatic Breast Cancer. New England Journal of Medicine. 2007; 357(26): 2666-2676. PMid:18160686. http://dx.doi.org/10.1056/NEJMoa072113

[48] Miles DW, et al. Phase III Study of Bevacizumab Plus Docetaxel Compared With Placebo Plus Docetaxel for the First-Line Treatment of Human Epidermal Growth Factor Receptor 2-Negative Metastatic Breast Cancer. Journal of Clinical Oncology. 2010; 28(20): 3239-3247. PMid:20498403. http://dx.doi.org/10.1200/JCO.2008.21.6457

[49] Robert NJ, et al. RIBBON-1: Randomized, Double-Blind, Placebo-Controlled, Phase III Trial of Chemotherapy with or Without Bevacizumab for First-Line Treatment of Human Epidermal Growth Factor Receptor 2-Negative, Locally Recurrent or Metastatic Breast Cancer. Journal of Clinical Oncology. 2011; 29(10): 1252-1260. PMid:21383283. http://dx.doi.org/10.1200/JCO.2010.28.0982

[50] von Minckwitz G, et al. Neoadjuvant Chemotherapy and Bevacizumab for HER2-Negative Breast Cancer. New England Journal of Medicine. 2012; 366(4): 299-309. PMid:22276820. http://dx.doi.org/10.1056/NEJMoa1111065

[51] Kim HR, et al. Multicentre phase II trial of bevacizumab combined with docetaxel-carboplatin for the neoadjuvant treatment of triple-negative breast cancer (KCSG BR-0905). Annals of Oncology. 2013; 24(6): 1485-1490. PMid:23380385.

http://dx.doi.org/10.1093/annonc/mds658

[52] Makhoul I, et al. Combined Neoadjuvant Chemotherapy With Bevacizumab Improves Pathologic Complete Response in Patients With Hormone Receptor Negative Operable or Locally Advanced Breast Cancer. American Journal of Clinical Oncology.

[53] Stephens PJ, et al. The landscape of cancer genes and mutational processes in breast cancer. Nature. 2012; 486(7403): 400-4. http://dx.doi.org/10.1038/nature11017

[54] Baselga J, et al. Everolimus in Postmenopausal Hormone-Receptor-Positive Advanced Breast Cancer. New England Journal of Medicine. 2012; 366(6): 520-529. PMid:22149876. http://dx.doi.org/10.1056/NEJMoa1109653

[55] Gonzalez-Angulo AM, et al. Open-label randomized clinical trial of standard neoadjuvant chemotherapy with paclitaxel followed by FEC versus the combination of paclitaxel and everolimus followed by FEC in women with triple receptor-negative breast cancer. Annals of Oncology. 2014; 25(6): 1122-1127. PMid:24669015. http://dx.doi.org/10.1093/annonc/mdu124

[56] Huober J, et al. Neoadjuvant chemotherapy with paclitaxel and everolimus in breast cancer patients with non-responsive tumours to epirubicin/cyclophosphamide (EC) +/- bevacizumab - results of the randomised GeparQuinto study (GBG 44). Eur J Cancer. 2013; 49(10): 2284-93. PMid:23541564. http://dx.doi.org/10.1016/j.ejca.2013.02.027

[57] Rydén L, et al. Epidermal growth factor receptor and vascular endothelial growth factor receptor 2 are specific biomarkers in triple-negative breast cancer. Results from a controlled randomized trial with long-term follow-up. Breast Cancer Research and Treatment. 2010; 120(2): 491-498. PMid:20135347. http://dx.doi.org/10.1007/s10549-010-0758-6

[58] Viale G, et al. Invasive ductal carcinoma of the breast with the "triple-negative" phenotype: prognostic implications of EGFR immunoreactivity. Breast Cancer Research and Treatment. 2009; 116(2): 317-328. PMid:18839307.

http://dx.doi.org/10.1007/s10549-008-0206-z

[59] Finn RS, et al. Estrogen Receptor, Progesterone Receptor, Human Epidermal Growth Factor Receptor 2 (HER2), and Epidermal Growth Factor Receptor Expression and Benefit from Lapatinib in a Randomized Trial of Paclitaxel With Lapatinib or Placebo As First-Line Treatment in HER2-Negative or Unknown Metastatic Breast Cancer. Journal of Clinical Oncology. 2009; 27(24): 3908-3915. PMid:19620495. http://dx.doi.org/10.1200/JCO.2008.18.1925

[60] Carey LA, et al. TBCRC 001: Randomized Phase II Study of Cetuximab in Combination With Carboplatin in Stage IV TripleNegative Breast Cancer. Journal of Clinical Oncology. 2012; 30(21): 2615-2623. PMid:22665533. http://dx.doi.org/10.1200/JCO.2010.34.5579 
[61] Baselga J, et al. Randomized Phase II Study of the Anti-Epidermal Growth Factor Receptor Monoclonal Antibody Cetuximab With Cisplatin Versus Cisplatin Alone in Patients With Metastatic Triple-Negative Breast Cancer. Journal of Clinical Oncology. 2013. http://dx.doi.org/10.1200/JCO.2012.46.2408

[62] P Sharma QK, Kimler BF, Klemp JR, et al. Abstract P1-11-07: Results of a Phase II Study of Neoadjuvant Platinum/Taxane Based Chemotherapy and Erlotinib for Triple Negative Breast Cancer. in Thirty-Third Annual CTRC-AACR San Antonio Breast Cancer Symposium. 2010. San Antonio, TX: Cancer Research.

[63] Baselga J, et al. Phase II Genomics Study of Ixabepilone as Neoadjuvant Treatment for Breast Cancer. Journal of Clinical Oncology. 2009; 27(4): 526-534. PMid:19075286. http://dx.doi.org/10.1200/JCO.2007.14.2646

[64] Helleday T. The underlying mechanism for the PARP and BRCA synthetic lethality: Clearing up the misunderstandings. Molecular oncology. 2011; 5(4): 387-393. PMid:21821475. http://dx.doi.org/10.1016/j.molonc.2011.07.001

[65] von Minckwitz G, et al. Cytoplasmic Poly(Adenosine Diphosphate-Ribose) Polymerase Expression Is Predictive and Prognostic in Patients with Breast Cancer Treated With Neoadjuvant Chemotherapy. Journal of Clinical Oncology. 2011; 29(16): $2150-2157$. PMid:21519019. http://dx.doi.org/10.1200/JCO.2010.31.9079

[66] O'Shaughnessy J, et al. Iniparib plus Chemotherapy in Metastatic Triple-Negative Breast Cancer. New England Journal of Medicine. 2011; 364(3): 205-214. PMid:21208101. http://dx.doi.org/10.1056/NEJMoa1011418

[67] O'Shaughnessy JSL, Danso MA, et al. A randomized phase III study of iniparib (BSI-201) in combination with gemcitabine/ carboplatin (G/C) in metastatic triple-negative breast cancer (TNBC) in Presented at the 2011 annual meeting of the American Society of Clinical Oncology. Chicago, IL; 2011.

[68] Llombart A, et al. SOLTI NeoPARP: A phase II, randomized study of two schedules of iniparib plus paclitaxel and paclitaxel alone as neoadjuvant therapy in patients with triple-negative breast cancer (TNBC). 2010.

[69] Liu X, et al. Iniparib Nonselectively Modifies Cysteine-Containing Proteins in Tumor Cells and Is Not a Bona Fide PARP Inhibitor. Clinical Cancer Research. 2012; 18(2): 510-523. PMid:22128301. http://dx.doi.org/10.1158/1078-0432.CCR-11-1973

[70] Patel AG, et al. Failure of Iniparib to Inhibit Poly(ADP-Ribose) Polymerase In Vitro. Clinical Cancer Research. 2012; 18(6): 1655-1662. PMid:22291137. http://dx.doi.org/10.1158/1078-0432.CCR-11-2890 